\section{SEZNAM POMEMBNEJŠIH NOVIH KNJIG KNJIŽNICE ODDELKA ZA KLASIČNO FILOLOGIJO ZA LETO 2000}

\section{HERMANN Diels (1848-1922) et la} science de l'Antiquité / huit exposés suivis de discussions par William $\mathrm{M}$. Calder III ... [et al.]. Entretiens préparés et présidés par William $M$. Calder III et Jaap Mansfeld. Avec la participation de Alex Leukart, François Paschoud et Olivier Reverdin. - Geneve, Fondation Hardt, cop. 1999. XV, 317 str. (Entretiens sur l'Antiquité classique, ISSN 0071 0822 ; t. 45) »Vandouvres-Geneve, 17-21 Aout 1998. .

ISBN 2-600-00745-8

COBISS-ID 17377378

RITUALS of power: From Late Antiquity to the Early Middle Ages. Ed. by Frans Theuws, Janet L. Nelson. Leiden-Boston-Köln, Brill, 2000. VIII, 503 str. (The Transformation Of The Roman world ; vol. 8).

ISBN 90-04-10902-1

COBISS-ID 11528546

La PAROLA nella citta: Studi sulla ricezione del teatro antico. Atti del convegno di Vittorio Veneto 24-25 novembre 1995 a cura di Alberto Camerotto e Renato Oniga. Udine, Forum, 1999. 92 str.

ISBN 88-86756-71-2

\section{COBISS-ID 12337250}

HANSON, V. D.: Who killed Homer? The demise of classical education and the recovery of Greek wisdom. Victor Davis Hanson, John Heath. New York, Free Press, 1998. XXIII, 290 str.

ISBN 0-684-84453-2

COBISS-ID 12489570
CORBATO, C.: Scritti di letteratura greca. Trieste, Giulio Bernardi, 1991. $\mathrm{XV}, 420$ str. (Pubblicazioni del Dipartimento di scienze dell'antichita / Universita degli studi di Trieste; 6$)$.

ISBN 88-85873-03-0

COBISS-ID 55959040

CONTE, G. B.: Latin literature : a history. Translated by Joseph B. Solodow, revised by Don Fowler and Glenn W. Most. Johns Hopkins Paperbacks ed. Baltimore-London, Johns Hopkins University Press, 1999, cop. 1994. XXXIII, 827 str.

ISBN 0-8018-6253-1 (pbk.)

COBISS-ID 12595298

MEINEKE, B.: Krakauer Neufund zum Alexanderroman des Ulrich von Etzenbach. Mit zwei Abbildungen. In Göttingen, Vandenhoeck\&Ruprecht, 1999. 86 str. (Nachrichten der Akademie der Wissenschaften in Göttingen. 1. Philologisch-historische Klasse, ISSN 0065-5287 ; Jg. 1999, Nr. 7).

COBISS-ID 12663394

ZBORNIK ob 100-letnici šolskega pouka v zgradbi sedanje Osnovne šole Prežihovega Voranca, Ljubljana. [Glavna urednica Aleksandra Pirkmajer Slokan, avtor prispevka Preteklost ljubljanske klasične gimnazije Vasilij Melik, fotografije Joco Žnidaršič ... et al.]. Ljubljana, Osnovna šola Prežihovega Voranca, 1999 (Ljubljana, Mat-format). 279 str.

COBISS-ID 104515840

LOQUELA vivida. Donum natalicium Nicolao Sallmann sexagesimum quintum annum agenti a fautoribus linguae Latinae vivae oblatum edidit Jürgen Blänsdorf. Würz- 
Schriften. Herausgegeben von Jürgen Leonhardt und Georg Ott. Stuttgart, Steiner, 2000. 277 str.

ISBN 3-515-07667-0

COBISS-ID 13392738

HEITSCH, E.: Grenzen philologischer Echtheitskritik: Bemerkungen zum 'Grossen Hippias'. Mainz (Akademie der Wissenschaften und der Literatur)Stuttgart (F. Steiner), 1999. 40 str. (Abhandlungen der Geistes- und sozialwissenschaftlichen Klasse / Akademie der Wissenschaften und der Literatur, ISSN 0002-2977; Jg. 1999, Nr. 4).

ISBN 3-515-07517-8

COBISS-ID 1516640

STRUVE, T.: Die Salier und das römische Recht: Ansätze zur Entwicklung einer säkularen Herrschaftstheorie in der Zeit des Investiturstreites. Mainz (Akademie der Wissenschaften und der Literatur)-Stuttgart (F. Steiner), 1999. 89 str. (Abhandlungen der Geistes- und sozialwissenschaftlichen Klasse / Akademie der Wissenschaften und der Literatur, ISSN 0002-2977; Jg. 1999, Nr. 5).

ISBN 3-515-07533-X

COBISS-ID 1516896

BLÖSSNER, N.: Musenrede und 'geometrische Zahl': ein Beispiel platonischer Dialoggestaltung ('Politeia' VIII, 545 c 8 - 547 a 7). Mainz (Akademie der Wissenschaften und der Literatur)Stuttgart (F. Steiner), 1999. 194 str. (Abhandlungen der Geistes- und sozialwissenschaftlichen Klasse / Akademie der Wissenschaften und der Literatur, ISSN 0002-2977; Jg. 1999, Nr. 7).

ISBN 3-515-07540-2

COBISS-ID 1515360
THIEL, R.: Simplikios und das Ende der neuplatonischen Schule in Athen. Mainz (Akademie der Wissenschaften und der Literatur)-Stuttgart (F. Steiner), 1999. 59 str. (Abhandlungen der Geistes- und Sozialwissenschaftlichen Klasse / Akademie der Wissenschaften und der Literatur, ISSN 0002-2977; Jg. 1999, Nr. 8).

ISBN 3-515-07551-8

COBISS-ID 1515616

ČOP, B.: Aurea Roma: učbenik za latinščino. Ljubljana, Oddelek za klasično filologijo Filozofske fakultete, 2000-. Zv. <1->. Dosedanja vsebina: Del 1.(2000) (Ljubljana, Bori). 231 str.

ISBN 961-227-069-4

COBISS-ID 109128704

WEST, M. L.: Frühe Interpolationen in der Ilias. Göttingen, Vandenhoeck\& Ruprecht, 1999. 11 str. (Nachrichten der Akademie der Wissenschaften in Göttingen. 1. Philologisch-historische Klasse, ISSN 0065-5287; Jg. 1999, Nr. 4).

\section{COBISS-ID 863328}

\section{Il CONVEGNO Dialetti galloitalici} dal nord al sud. Realta e prospettive (1994; Piazza Armerina). Convegno di studi su dialetti galloitalici dal nord al sud: realta e prospettive, Piazza Armerina, 7-9 aprile 1994, a cura di Salvatore C. Trovato. [S. 1.], Il lunario, 1999. 390 str. (Progetto Galloitalici. Saggi e materiali; 2)

ISBN 88-8181-032-8

COBISS-ID 14186338

GIMNAZIJA Poljane (Ljubljana): Včeraj, danes, vedno. Zbornik ob 100-letnici Gimnazije Poljane (19002000) [uredniški odbor Milena Bon (glavna urednica) ... [et al.], foto- 
grafije Marjan Paternoster ... et al.] . Ljubljana, Gimnazija Poljane, 2000 (Litija, Aco). 112 str.

COBISS-ID 109797376

TOWNS and their territories between late antiquity and the early Middle Ages. Edited by G.P. Brogiolo, N. Gauthier, N. Christie. LeidenBoston-Köln, Brill, 2000. XVII, 403 str. (The Transformation Of The Roman World, ISSN 1386-4165; vol. 9). ISBN 90-04-11869-1

\section{COBISS-ID 13735010}

The LONG eighth century. Edited by Inge Lyse Hansen, Chris Wickham. Leiden-Boston-Köln, Brill, 2000. X, 388 str. (The Transformation Of The Roman World, ISSN 1386-4165; vol. 11).

ISBN 90-04-11723-7

COBISS-ID 13786466
ANTIQUARIUM Cracoviense: Les vases et les monnaies grecs de la collection de l'Université Jagellonne de Cracovie et du Musée National de Cracovie Collection E. Czapski. Exposition a l'occasion de la 73-eme Session de l'Union Académique Internationale / Le Musée Princes Czartoryski... [et al.]; auteurs Evdoksia Papuci-Władyka [et] Jarosław Bodzek, rédacteur Elżbieta Fiałek. Cracovie, L'Académie Polonaise des Sciences et des Lettres $=$ Polish Academy of Arts and Sciences, 1999. 14 str.

ISBN 83-86956-62-3 COBISS-ID 14256738 